\title{
EL ARTE DE PROLONGAR LA MEMORIA
}

Jorge Iván Ortiz Tangarife 


\section{THE ART OF PROLONGING MEMORY}

\section{ABSTRACT}

The book is memory and the edition of a book becomes the art of prolonging memory. The editing process is an art based on the details and the editor should aim to give the reader an unforgettable experience without neglecting the resources used for its purpose.

Key words: Edition, Book, Memory, Art.

\section{RESUMEN}

El libro es memoria y la edición de un libro se convierte en el arte de prolongar la memoria. El proceso de edición es un arte basado en los detalles y el editor debe propender por otorgar al lector una experiencia inolvidable sin descuidar los recursos utilizados para su propósito.

Palabras clave: Edición, Libro, Memoria, Arte.

\section{AUTOR}

Jorge Iván Ortiz Tangarife

Ingeniero Administrador, Universidad Nacional de Colombia. Estudiante de Literatura, Universidad Autónoma de Bucaramanga

Correo electrónico: jorgeortiz8@gmail.com 
Me gustaría comenzar definiendo lo que para mí es un libro. Podría decir en una sola palabra que un libro es memoria. Siendo más explícito, diría que un libro recoge la memoria tanto individual (la del escritor) como colectiva (la de la sociedad que se desarrolla en la época en la que el libro es publicado). El escritor plasma en su libro su conocimiento, sus vivencias, su concepción del mundo, sus ideas más lúcidas e incluso las más carentes de convencionalismo; en síntesis, su memoria, que revela y pone al servicio de una sociedad capaz de abstraerla de las páginas. Pero también, el libro tiene la capacidad de propagar y perpetuar dicha memoria. La propaga en aquellos individuos lectores, ya sean contemporáneos del libro como objeto publicado, o pertenecientes a tiempos futuros en los que el libro permanece en su presente, pero con la habilidad de adaptarse a cualquier tiempo. Y la perpetúa en aquellas sociedades que leen el libro una y otra vez, y que retienen de él lo que podría ser útil en su contexto determinado. Como dice Fernando Báez (2004) en su introducción a la Historia universal de la destrucción de libros, "ese vínculo poderoso entre libro y memoria hace que un texto deba ser visto como pieza clave del patrimonio cultural de una sociedad, $y$, por supuesto, de la humanidad entera" (p.22). Por lo tanto, así como la memoria es la facultad de recordar, así mismo el libro es el contenedor de memorias eternas que no deben ser olvidadas.

Ahora bien, si un libro es memoria y si escribir es dar vida a una historia, editar es dar vida a un libro, es decir, es el arte de prolongar la memoria. Por lo tanto, el editor posibilita que una historia viva revolucione las vidas de los lectores que pueden acercarse a ella a través del libro vivo. Es así como el editor se convierte en un hacedor de vida a partir de la vida, en un engendrador de cultura a raíz de una historia, y en un procreador de arte desde el arte.
El editor es aquel eslabón que permite la proximidad entre el autor y el lector. Sin el editor, difícilmente podría darse esta unión, que en ningún momento es física, sino metafísica. Es un facilitador del encuentro de dos almas por medio del libro. Felipe González, editor de Laguna Libros dice que "la labor editorial no se reduce a producir libros, también comprende conectar esos libros con los lectores y, en ese mismo sentido, ayudar a formar públicos ofreciendo experiencias y contenidos paralelos al libro". Así que la edición, aunque parezca extraño, no debería acabar con la producción final del libro, debe trascender al público lector para forjar lazos perdurables entre ellos y el libro, no el objeto físico, sino la historia viva hecha carne (o en este caso, papel).

El proceso de edición requiere de imaginación, casi en igual dosis que la que necesitó el escritor para generar la historia, con el fin de que la versión final del libro se acerque a lo que el autor tenía en mente, pero también a lo que los lectores esperan en términos de calidad, estilo, belleza y, en algunos casos, precio. Así lo indica Gabriel Iriarte, director editorial de Random House Colombia: "el editor debe tratar de publicar contenidos de calidad, tanto en la forma como en el contenido, tanto en ficción como en no ficción. Por supuesto que simultáneamente tiene la obligación de hacer de su actividad un negocio rentable". La edición es arte, y un arte basado en los detalles. Cada pieza debe encajar a la perfección, como en un reloj. Y para que esto ocurra, se requieren recursos: capital, personas y tiempo, que muchas veces corre en contra del editor. Estos recursos necesarios deben ser contabilizados, porque, aunque arte, también es negocio y, como tal, debe ser redituable para los propietarios. El problema del equilibrio entre costo y calidad al que se enfrenta el editor, es el mismo que encara cualquier empresario que fabrica su producto 
y lo lanza al mercado: no puede ser tan costoso que signifique un precio alto poco asequible para los consumidores, ni puede ser de baja calidad que ningún comprador esté dispuesto a adquirirlo. La diferencia tal vez más importante, es que el libro es un bien de uso único (la mayoría de las veces) cuyo valor depende más de la experiencia del lector con él, de la satisfacción durante el breve lapso de lectura, y no tanto de su uso prolongado. Más que un producto, un libro es un servicio, casi comparable con un viaje vacacional, en el que el editor debe asegurarse de que su cliente viva la más excitante de sus experiencias lectoras. Es, en definitiva, esta experiencia la que le da valor al libro, la que permite juzgar su precio, muchas veces invaluable por la gratificación simbólica que otorga. El editor, entonces, para convertir el libro en una experiencia inolvidable, en una vida vivificante para el lector, debe dirigir a plenitud el proceso y cerciorarse de cada aspecto: cubierta, ilustraciones, tipo de papel, tamaño de letra, fuente, estilo, correcciones, entre otros, e igualmente tener fuertes vínculos con distribuidores comprometidos, para que el libro llegue finalmente a su destino.

Como propone Gabriel Iriarte, "el editor tiene una responsabilidad social en cuanto divulga contenidos que van a un público muy amplio, que incluye niños, jóvenes, adultos, mujeres, hombres, etc.". El editor no sólo debe preocuparse por la calidad física del libro, sino también por la calidad del contenido que, a través de su empresa, llegará a un público diverso. Es preciso que un editor no esté impulsado solamente por el dinero y que sus acciones no se lleven a cabo a costa del buen nombre de una persona o institución, e incluso a expensas de publicar contenido falso o perjudicial, o contenido con baja calidad literaria, entre otros. El editor debe sentir pasión por su profesión y tener siempre presente que cada libro publicado bajo su sello editorial, tendrá un impacto directo en la sociedad y en la cultura de su región, de su país o, quizá, del mundo entero.

Son muchos los aspectos que un editor debe tener en cuenta a la hora de publicar un libro. Sin embargo, como dice Lucía Donadío, editora de Sílaba, si un editor siente amor por los libros ( $\mathrm{y}$ deseo de hacer perdurar la memoria), además del deseo de mostrar al mundo talentos ocultos y enriquecer la cultura de un territorio con nuevas obras, ya tiene gran parte del camino recorrido para fecundar vidas literarias. Lo demás serán gajes del oficio que se podrán ir subsanando con el tiempo.

\section{REFERENCIAS}

Báez, F. (2004). Historia universal de la destrucción de libros. De las tablillas sumerias a la guerra de Irak. Madrid: Ediciones Destino.

Revista Arcadia. (2016). "Emma Reyes ha sido la santa matrona de Laguna Libros". Recuperado de: http:// www.revistaarcadia.com/agenda/articulo/felipe-gonzalez-laguna-libros-entrevista/60984

Revista Arcadia. (2016). "La clave es el equilibrio entre calidad y ventas". Recuperado de: http://www.revistaarcadia.com/libros/articulo/gabriel-iriartedirector-editorial-de-penguin-random-house/60653

Citar este artículo como: Ortiz, J. (2017). “El arte de prolongar la memoria". En: Revista La Tercera Orilla (19). Bucaramanga: Universidad Autónoma de Bucaramanga. 